Research Article

\title{
Tunable $\mathrm{SnO}_{2}$ Nanoribbon by Electric Fields and Hydrogen Passivation
}

\author{
Xin-Lian Chen, Bao-Jun Huang, Chang-Wen Zhang, Ping Li, and Pei-Ji Wang \\ School of Physics, University of Jinan, Jinan 250022, China \\ Correspondence should be addressed to Pei-Ji Wang; ss_wangpj@ujn.edu.cn
}

Received 12 December 2016; Accepted 22 February 2017; Published 20 March 2017

Academic Editor: Shu Seki

Copyright (C) 2017 Xin-Lian Chen et al. This is an open access article distributed under the Creative Commons Attribution License, which permits unrestricted use, distribution, and reproduction in any medium, provided the original work is properly cited.

\begin{abstract}
Under external transverse electronic fields and hydrogen passivation, the electronic structure and band gap of tin dioxide nanoribbons $\left(\mathrm{SnO}_{2} \mathrm{NRs}\right)$ with both zigzag and armchair shaped edges are studied by using the first-principles projector augmented wave (PAW) potential with the density function theory (DFT) framework. The results showed that the electronic structures of zigzag and armchair edge $\mathrm{SnO}_{2} \mathrm{NRs}$ exhibit an indirect semiconducting nature and the band gaps demonstrate a remarkable reduction with the increase of external transverse electronic field intensity, which demonstrate a giant Stark effect. The value of the critical electric field for bare $\mathrm{Z}-\mathrm{SnO}_{2} \mathrm{NRs}$ is smaller than A-SnO $\mathrm{O}_{2} \mathrm{NRs}$. In addition, the different hydrogen passivation nanoribbons $\left(\mathrm{Z}-\mathrm{SnO}{ }_{2} \mathrm{NRs}-\right.$ $2 \mathrm{H}$ and $\mathrm{A}-\mathrm{SnO}_{2} \mathrm{NRs}-\mathrm{OH}$ ) show different band gaps and a slightly weaker Stark effect. The band gap of A-SnO ${ }_{2} \mathrm{NRs}-\mathrm{OH}$ obviously is enhanced while the $\mathrm{Z}-\mathrm{SnO}_{2} \mathrm{NRs}-2 \mathrm{H}$ reduce. Interestingly, the $\mathrm{Z}-\mathrm{SnO}_{2} \mathrm{NRs}-\mathrm{OH}$ presented the convert of metal-semiconductormetal under external transverse electronic fields. In the end, the electronic transport properties of the different edges $\mathrm{SnO}_{2} \mathrm{NRs}$ are studied. These findings provide useful ways in nanomaterial design and band engineering for spintronics.
\end{abstract}

\section{Introduction}

The low-dimensional materials have attracted extensive attentions due to their excellent physical properties and novel electronic properties in the past decade. The graphene is especially discovered in 2004 [1]; it provides the new foundation for the research of low-dimensional systems [26]. However, graphene still faces many challenges, such as toxicity, lacking an intrinsic band gap, and incompatibility with current silicon-based electronic technology, which are in the way of the applications of graphene in electric devices [7]. Since the discovery of graphene, various 2D materials have been predicted and synthesized [8,9], particularly, the group IV ( $\mathrm{Si}, \mathrm{Ge}$, and $\mathrm{Sn}$ ) analogs of graphene. The stanene may be a competitive candidate of graphene, because of the high conductivity of stanene [10], and its electric structure can be easily tuned [11]. The existing works have studied the effect of stain, substrate, external electric field, modification by functional groups, and so on [12,13]. As in Modarresi et al. [14] tuning the band gap by the strain effect and external electric field ( $E$-field) tends to open an energy gap predicated by Ren et al. [15]. In addition, Li and Zhang [16] studied tunable electronic structures and magnetic properties in twodimensional stanene. Recently, the experiment and theory of one-dimensional (1D) graphene nanoribbons (GNRs) have been widely reported. In theoretical research, the zigzag GNRs can display the properties of half-metallicity by applying transverse electric field, promising candidate materials for spintronic devices [2,4]. The electronic and optical properties of GNRs can be also modulated by changing edge termination [17]. Experimental results prove that the GNRs with various widths and crystallographic orientations are more facilitative and flexible than carbon nanotubes (CNTs), through standard lithographic procedures or chemical methods [3, 5]. Inspired by the fruitful results based on GNRs, recently a lot of interest has been drawn to nanoribbons of wide bandgap semiconductor, such as boron nitride (BNNRs) [18], molybdenum disulfide ( $\left.\mathrm{MoS}_{2} \mathrm{NRs}\right)[19,20]$, and zinc oxide (ZnONRs) [21]. In the calculation of zinc oxide (ZnONRs), the polarized spin density of states is a function of the nanoribbons width. Kou et al. demonstrate that the band gap of $\mathrm{ZnO}$ nanoribbon can be reduced monotonically with increasing transverse field strength, demonstrating a giant Stark effect [22]. The titania nanoribbons $\left(\mathrm{TiO}_{2} \mathrm{NRs}\right)$ also 


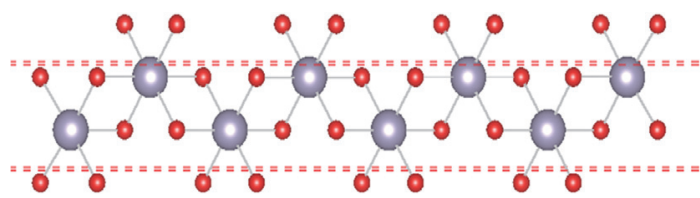

(a)

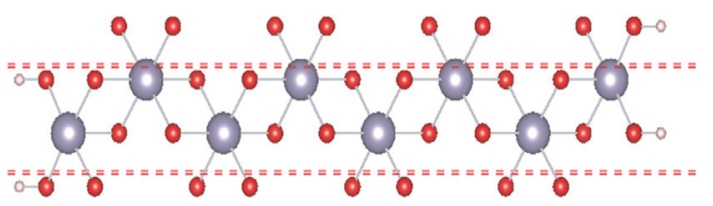

(b)

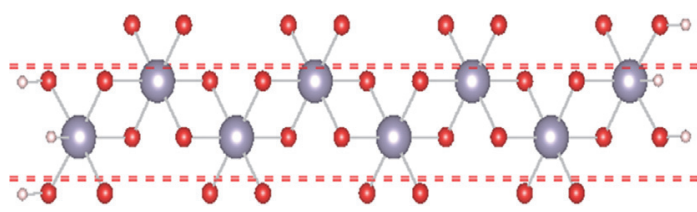

(c)

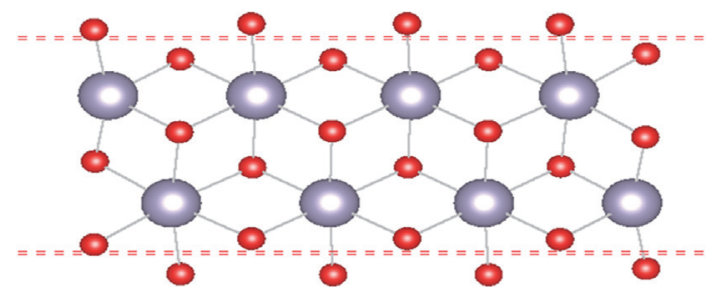

(d)

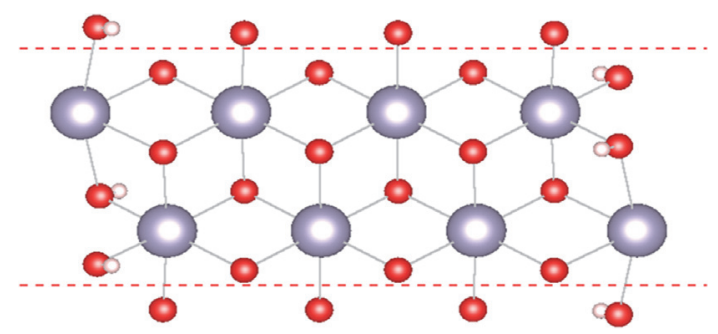

(e)

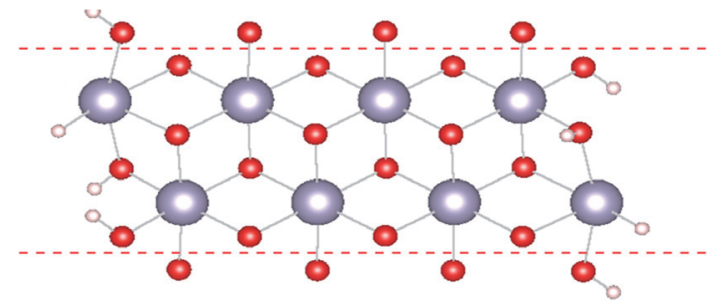

(f)

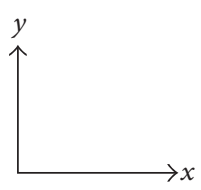

(g)

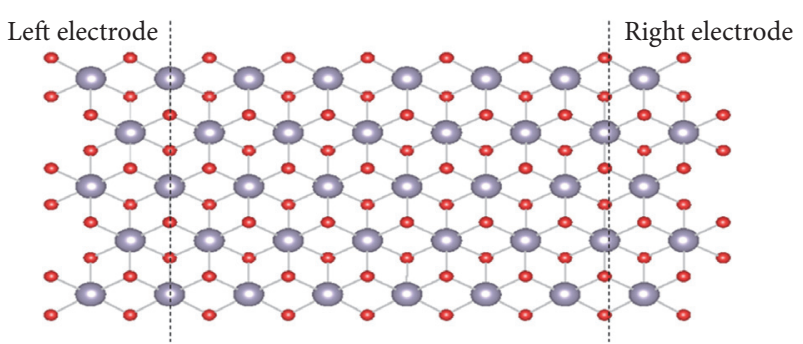

(h)

FIGURE 1: The structure model of $(4 \times 1 \times 1)$ zigzag and $(1 \times 4 \times 1)$ armchair $\mathrm{SnO}_{2}$ nanoribbon for different hydrogen passivation $(\mathrm{a}-\mathrm{f})$ and the transport model (h) ( $y$ is the growth direction of nanoribbons and $x$ is the direction of external electronic field). The big gray balls are $S n$ atoms, the small red balls are $\mathrm{O}$ atoms and the pink balls are $\mathrm{H}$ atom. In addition, the red-dotted lines would represent the unit cell.

predicate that the edge states and band gaps are sensitive to edge termination and ribbon width [23].

Tin dioxide $\left(\mathrm{SnO}_{2}\right)$ is also a typical wide-gap semiconductor with band gap $E_{g}=3.6 \mathrm{eV}$, because of the fascinating electronic properties and optical transparency they have been widely used in photovoltaic devices, transparent conducting electrodes, solar cells, chemical gas sensors, and panel displays [24-30]. Recently, many theoretical researches have reported the electronic structures and geometric properties of $\mathrm{SnO}_{2}$ nanomaterials using first-principles [31, 32]. More fortunately, the ultrathin $\mathrm{SnO}_{2}$ nanofilm and one-dimensional (1D) $\mathrm{SnO}_{2}$ nanoribbon have been synthesized by thermal evaporation and postprocessing in experiments [33]. Motivated by the outstanding properties of GNRs and wide band gap semiconductor, we put our emphasis on the $\mathrm{SnO}_{2}$ nanoribbons, which may obtain more excellent achievement. In previous work, Huang et al. study the electronic structure bandgap modulations of $\mathrm{SnO}_{2}$ nanoribbon by ribbon width [34].

In this paper, we perform first-principles calculations to study the bandgap modulations, electronic structures, and hydrogen passivation of $\mathrm{SnO}_{2} \mathrm{NRs}$ under transverse electric fields. We found that both armchair and zigzag $\mathrm{SnO}_{2} \mathrm{NRs}$ without hydrogen passivation are semiconductor with indirect gap and the semiconductor-metal transition occurs at a certain critical electric field. More interesting, partially passivating all the edge $\mathrm{O}$ atoms and passivating all the $\mathrm{O}$ and $\mathrm{Sn}$ atoms of $\mathrm{SnO}_{2}$ NRs could present the distinct properties. 


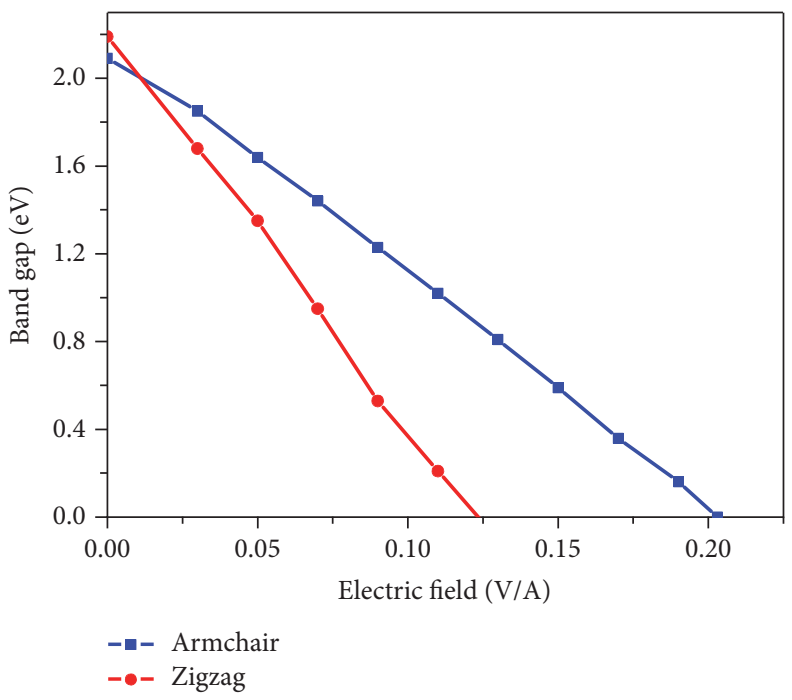

FIGURE 2: Band gap evolution under various external electric fields in bare $\mathrm{Z}-\mathrm{SnO}_{2} \mathrm{NRs}$ and $\mathrm{A}-\mathrm{SnO}_{2} \mathrm{NRs}$.

Our work offers a promising route toward modulating lowdimensional $\mathrm{SnO}_{2}$ nanomaterials bandgap which have potential applications in nanoscale optical devices.

\section{Model and Computational Methods}

The electronic and optical properties of $1 \mathrm{D} \mathrm{SnO}_{2}$ nanostructures are performed with the spin-polarized first-principles methods as implemented in the Vienna ab initio simulation package (VASP) [35] and the subsequent electronic transport properties calculations are performed by the Atomistix Toolkit Package (ATK). Projector augmented wave (PAW) potentials and the Perdew et al. [36] function under the spin-polarized generalized gradient correlation are used to describe the exchange and correlation interaction. The supercells are large enough to ensure that the vacuum space is at least $15 \AA$, so that the interaction between nanostructures and their periodic images can be safely avoided. Following the Monkhorst-Pack scheme [37], $12 \mathrm{k}$ points were used to sample the $1 \mathrm{D}$ Brillouin zone, and the convergence threshold was set as $10^{-4} \mathrm{eV}$ in energy and $0.02 \mathrm{eV} / \AA$ in force. The valence electrons for the $\mathrm{Sn}, \mathrm{O}$, and $\mathrm{Ag}$ are 14 (Sn: $4 d^{10} 5 s^{2} 5 p^{2}$ ), 6 (O: $\left.2 s^{2} 2 p^{4}\right)$, and $11\left(4 d^{10} 5 s^{1}\right)$. The positions of all the atoms in the supercell were fully relaxed during the geometry optimizations.

The model structures of $\mathrm{SnO}_{2} \mathrm{NRs}$ were generated by cutting an $\mathrm{SnO}_{2} \mathrm{NS}$ (tin dioxide nanosheets) along armchair and zigzag orientations, which are referred to as zigzag $\mathrm{SnO}_{2}$ nanoribbons ( $\mathrm{Z}-\mathrm{SnO}_{2} \mathrm{NRs}$ ) and armchair $\mathrm{SnO}_{2}$ nanoribbons $\left(\mathrm{A}-\mathrm{SnO}_{2} \mathrm{NRs}\right.$ ), as shown in Figure 1. The external electric field is modelled by transversely adding a sawtooth-like potential to the nanoribbon. We should explain that the DFT functional always underestimates the band gap of semiconductors, but it is powerful to predict a correct trend toward the band gap change and efficiently unveil the physical mechanism $[38,39]$.

\section{Results and Discussion}

3.1. The Band Gap Modulation under External Electric Field in Bare $\mathrm{SnO}_{2}$ Nanoribbon. In both zigzag nanoribbon and armchair nanoribbon, the original package contains 8 tin atoms and 16 oxygen atoms. So, in our calculations we choose zigzag and armchair $\mathrm{SnO}_{2}$ nanoribbons with width $N=$ 8. The results show that the electronic structures of zigzag and armchair edge $\mathrm{SnO}_{2}$ nanoribbon exhibit an indirect semiconducting nature with the band gap of about $2.19 \mathrm{eV}$ and $2.08 \mathrm{eV}$, respectively, which are well consistent with our previous results [34]. Firstly, we modulate band gaps of the bare $\mathrm{SnO}_{2}$ nanoribbon by applying the transverse electronic fields. Considering the symmetrical structure of the $\mathrm{Z}-\mathrm{SnO}_{2} \mathrm{NRs}$ and $\mathrm{A}-\mathrm{SnO}_{2} \mathrm{NRs}$, the external electric fields are added to the $x$ direction in Figure 1. The evolution of the band gaps for $\mathrm{Z}-\mathrm{SnO}_{2} \mathrm{NRs}$ and $\mathrm{A}-\mathrm{SnO}_{2} \mathrm{NRs}$ under different external electric field intensity is shown in Figure 2. From Figure 2, the band gaps of bare $\mathrm{Z}-\mathrm{SnO}_{2} \mathrm{NRs}$ and $\mathrm{A}-\mathrm{SnO}_{2} \mathrm{NRs}$ demonstrate a remarkable reduction when an external electric field is applied. The band gaps eventually closed when the electric field reached a critical value for each specified $\mathrm{SnO}_{2}$ nanoribbon; this phenomenon is similar to the armchair $\mathrm{ZnO}$ nanoribbon [22]. The values of the critical electric field for bare $\mathrm{Z}-\mathrm{SnO}_{2} \mathrm{NRs}$ and $\mathrm{A}-\mathrm{SnO}_{2} \mathrm{NRs}$ are $0.124 \mathrm{~V} / \AA$ and $0.210 \mathrm{~V} / \AA$, respectively. This suggests that the semiconductormetal transition occurs at a certain value of critical electric field for $\mathrm{Z}-\mathrm{SnO}_{2} \mathrm{NRs}$ compared to $\mathrm{A}-\mathrm{SnO}_{2} \mathrm{NRs}$.

To further investigate the underlying physical mechanism, the charge redistribution of $\mathrm{Z}-\mathrm{SnO}_{2} \mathrm{NRs}$ and A$\mathrm{SnO}_{2} \mathrm{NRs}$ is studied with and without an external electronic field, respectively. Figures 3(a)-3(b) show the band structure, density of state (DOS), and the corresponding charge densities for the conduction band minimum (CBM) and the valence band maximum (VBM) of $\mathrm{Z}-\mathrm{SnO}_{2} \mathrm{NRs}$ and $\mathrm{A}-\mathrm{SnO}_{2} \mathrm{NRs}$ at $0 \mathrm{~V} / \mathrm{A}$ (a) and $0.13 \mathrm{~V} / \mathrm{A}$, respectively. From Figure 3, the band gap of the $\mathrm{Z}-\mathrm{SnO}_{2} \mathrm{NRs}$ is $2.19 \mathrm{eV}$ under the electric field of 

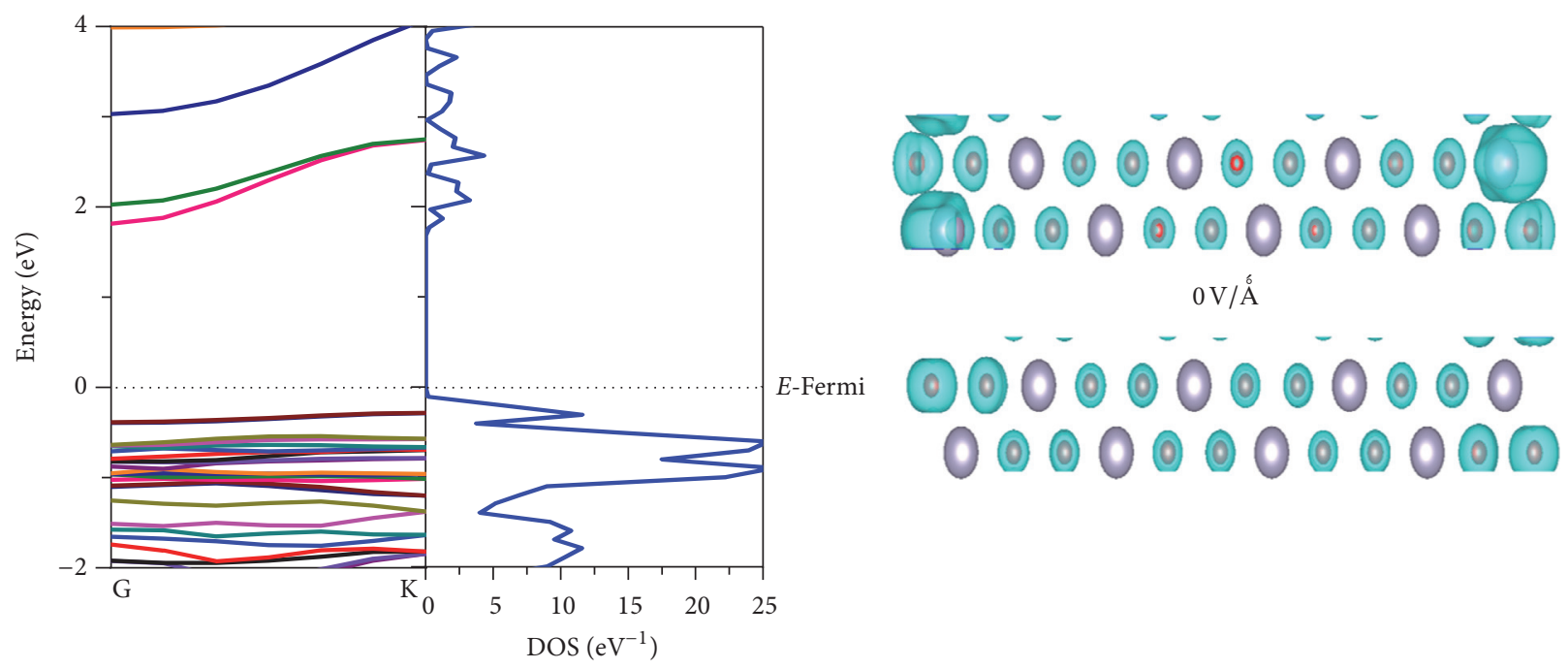

(a)
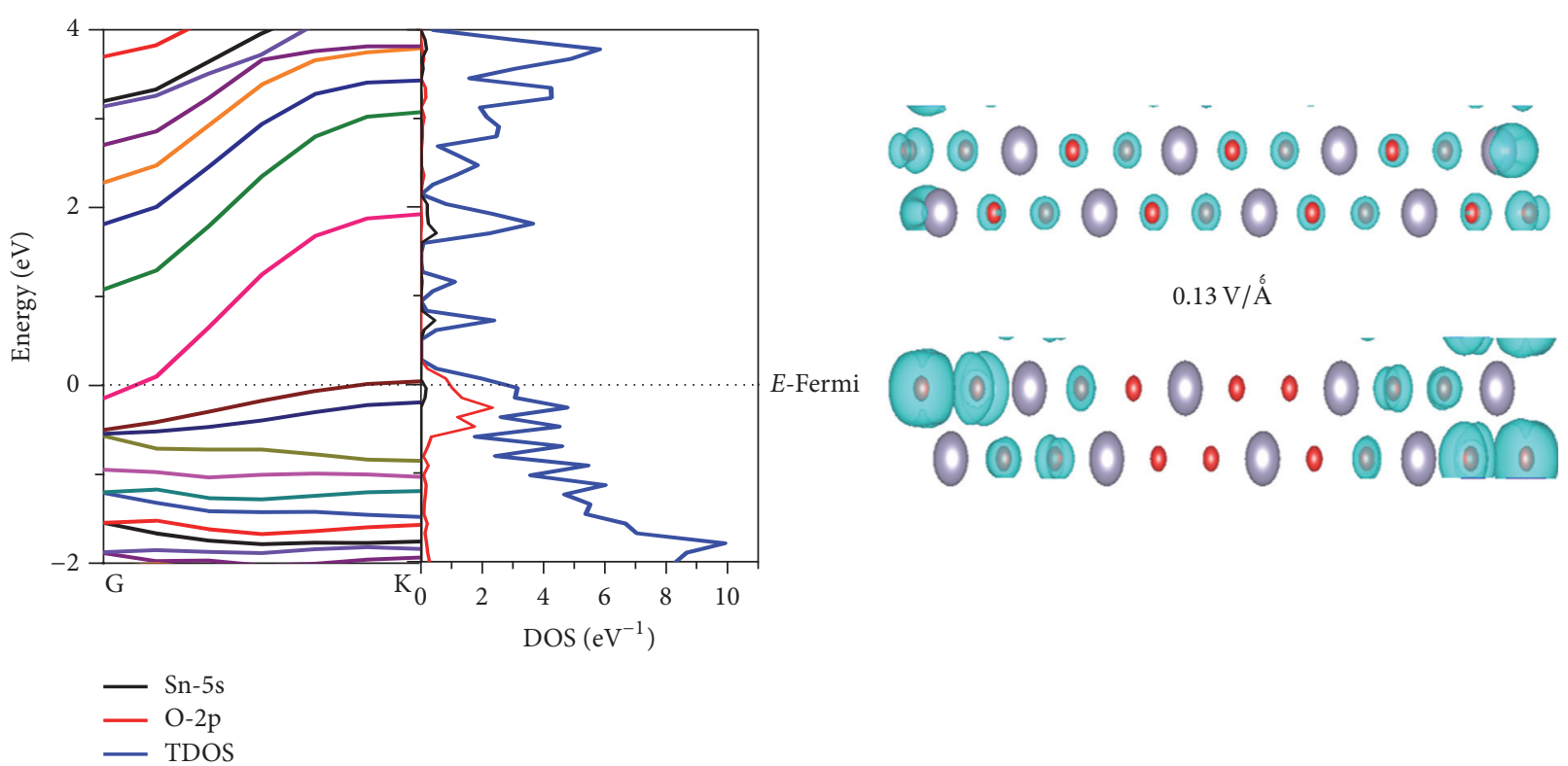

(b)

FIgURE 3: Band structure and DOS (left) and the corresponding charge densities for CBM (right upper) and $\mathrm{VBM}$ (right lower) of Z-SnO $\mathrm{NRs}$

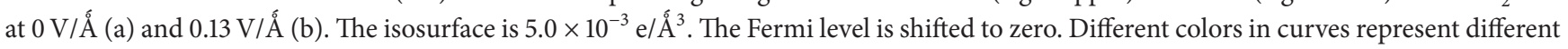
energy levels.

$0 \mathrm{~V} / \mathrm{A}$. While the band gap of the $\mathrm{Z}-\mathrm{SnO}_{2} \mathrm{NRs}$ obviously becomes narrow and the DOS near the Fermi level are mainly ascribed to $\mathrm{O} 2 \mathrm{p}$ states and $\mathrm{Sn} 5 \mathrm{~d}$ states under the electric field of $0.13 \mathrm{~V} / \mathrm{A}$. In addition, from Figure 3 (charge densities for CBM and VBM of Z-SnO ${ }_{2} \mathrm{NRs}$ ), we can find that when we applied an external electric field $(0.13 \mathrm{~V} / \AA \dot{A})$, the charge is evenly distributed, whereas VBM is a different localized state in which the wave function mainly focused on both sides of the $\mathrm{O}$ atoms for the whole nanoribbon.

In Figures 4(a)-4(b), band structure, DOS, and the corresponding charge densities for the CBM and VBM of

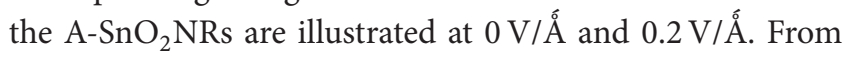

Figure 4 we can find that the band gap of $\mathrm{A}-\mathrm{SnO}_{2} \mathrm{NRs}$ is $2.08 \mathrm{eV}$ without electric field; the charge density of the CBM and VBM is different from the $\mathrm{Z}-\mathrm{SnO}_{2} \mathrm{NRs}$ and is edge state with wave function localized at the edge of the $\mathrm{O}$ atoms. The band gap becomes narrower and the DOS near the Fermi level is mainly caused by $\mathrm{O} 2 \mathrm{p}$ states with the external electric field of $0.2 \mathrm{~V} / \AA \AA$. Meanwhile, it is found that the charges are redistributed and the phenomenon of giant Stark effects appears, which is similar to $\mathrm{ZnO}$ nanoribbons [22, 40]. For the $\mathrm{Z}-\mathrm{SnO}_{2} \mathrm{NRs}$, with the external electric field, the band gap is similar to the $\mathrm{A}-\mathrm{SnO}_{2} \mathrm{NRs}$. In addition, the distribution of the wave function for CBM has no obvious change, while 

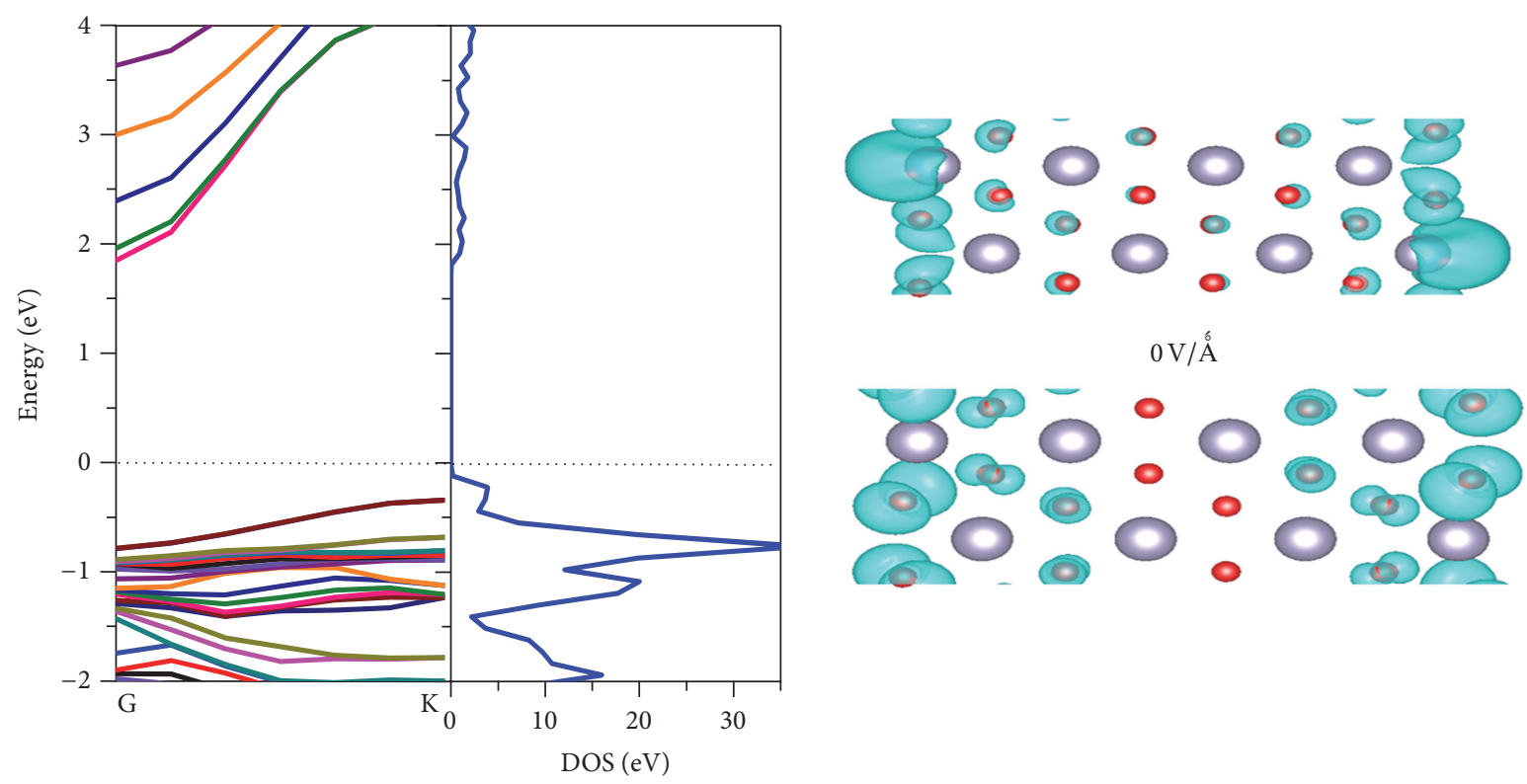

(a)
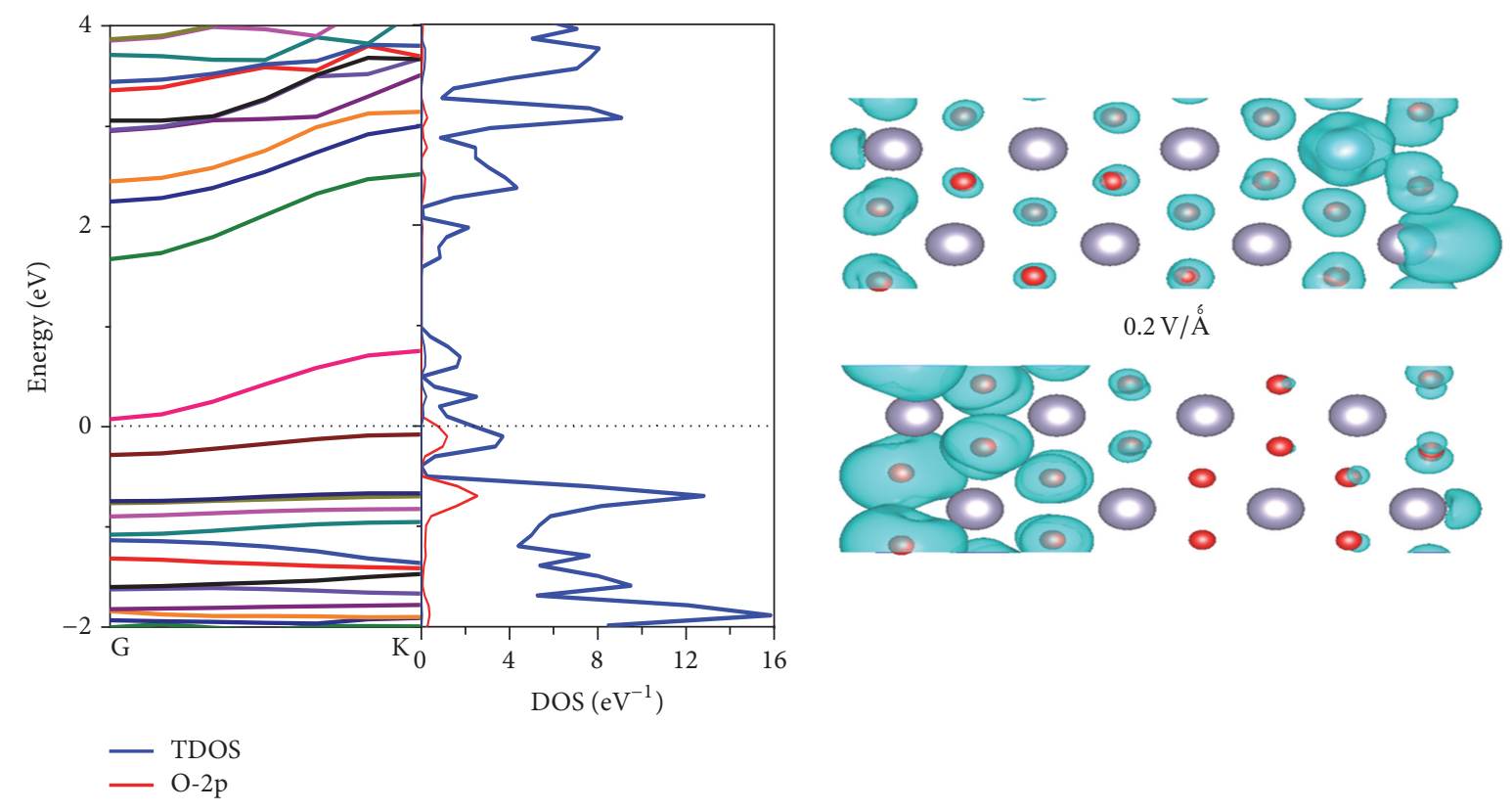

(b)

FIGURE 4: Band structure and DOS (left) and the corresponding charge densities for CBM (right upper) and VBM (right lower) of A-SnO $\mathrm{NRs}$

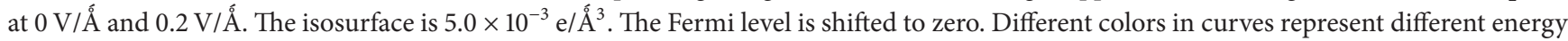
levels.

the wave functions of VBM gather to the edge $\mathrm{O}$ atoms and hardly have any wave function at the ribbon center, as shown in Figure 3(b). All in all, when we apply external electric field, due to the splitting of subbands levels caused by the charge redistribution, this makes the band gaps of $\mathrm{SnO}_{2}$ nanoribbons decrease.

3.2. The Band Gap Modulation under External Electric Field in Hydrogen Passivation $\mathrm{SnO}_{2}$ Nanoribbon. To explore the effect of edge hydrogen $(\mathrm{H})$ termination on the electronic properties of the different $\mathrm{SnO}_{2}$ nanoribbons, two different ways of nanoribbon edge hydrogen termination have been studied: (i) the edge of $\mathrm{Sn}$ and $\mathrm{O}$ atoms are passivated with $\mathrm{H}$ atoms (denoted $\mathrm{SnO}_{2} \mathrm{NR}-2 \mathrm{H}$ ) and (ii) the edge of $\mathrm{O}$ atoms are passivated (denoted $\mathrm{SnO}_{2} \mathrm{NR}-\mathrm{OH}$ ), as shown in Figures $1(\mathrm{~b})-1(\mathrm{c})$ and $1(\mathrm{e})-1(\mathrm{f})$. It is important for evaluation of the stability of $\mathrm{SnO}_{2} \mathrm{NRs}$ because it can determine whether this nanostructure can be realized experimentally. The relative 


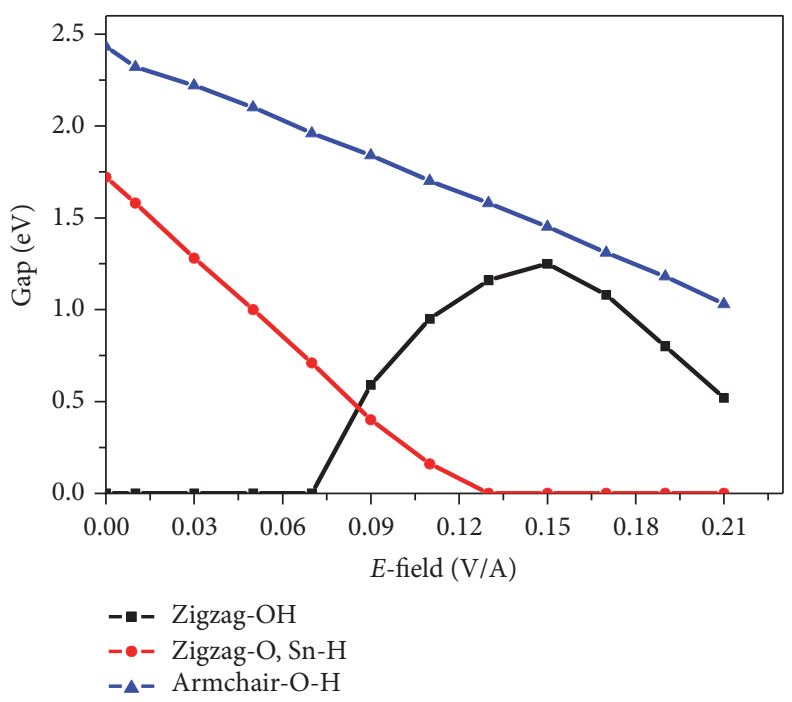

FIGURE 5: Band gap evolutions under various external electric fields in hydrogen passivation zigzag and armchair $\mathrm{SnO}_{2}$ nanoribbon with width $N=8$.

TABLE 1: Binding energy (per atom) and band gap of $\mathrm{SnO}_{2} \mathrm{NRs}$ for different configurations.

\begin{tabular}{lcc}
\hline Configurations & Binding energy & Band gap \\
\hline $\mathrm{Z}-\mathrm{SnO}_{2} \mathrm{NR}$ & $2.54 \mathrm{eV}$ & $2.50 \mathrm{eV}$ \\
$\mathrm{A}-\mathrm{SnO}_{2} \mathrm{NR}$ & $2.44 \mathrm{eV}$ & $2.09 \mathrm{eV}$ \\
$\mathrm{Z}-\mathrm{SnO}_{2} \mathrm{NR}-\mathrm{OH}$ & $2.75 \mathrm{eV}$ & $0 \mathrm{eV}$ \\
$\mathrm{A}^{-\mathrm{SnO}_{2} \mathrm{NR}-\mathrm{OH}}$ & $2.64 \mathrm{eV}$ & $2.43 \mathrm{eV}$ \\
$\mathrm{Z}_{-} \mathrm{SnO}_{2} \mathrm{NR}-2 \mathrm{H}$ & $2.41 \mathrm{eV}$ & $1.72 \mathrm{eV}$ \\
$\mathrm{A}-\mathrm{SnO}_{2} \mathrm{NR}-2 \mathrm{H}$ & $2.50 \mathrm{eV}$ & $2.44 \mathrm{eV}$ \\
\hline
\end{tabular}

stability of bare and $\mathrm{H}$ passivated $\mathrm{SnO}_{2} \mathrm{NRs}$ is determined by the binding energy $\left(E_{b}\right) . E_{b}$ is defined as $E_{b}=\left(\sum n_{i} E_{i}-\right.$ $\left.E_{\text {tot }}\right) / \sum n_{i}$, where $i$ represents different elements of $S n$ and $\mathrm{O}, n_{i}$ and $E_{i}$ are the number and chemical potential for the corresponding element, respectively, and $E_{\text {tot }}$ is the total free energy of system. According to the laws of thermodynamics, the larger the binding energy is, the more stable the structure is. The values of $E_{b}$ for different configurations of $\mathrm{SnO}_{2} \mathrm{NRs}$ are shown in Table 1.

From Table 1, the $\mathrm{SnO}_{2} \mathrm{NR}-\mathrm{OH}$ has a higher binding energy than bare $\mathrm{SnO}_{2} \mathrm{NRs}$ and $\mathrm{SnO}_{2} \mathrm{NRs}-2 \mathrm{H}$. The binding energies of $\mathrm{Z}-\mathrm{SnO}_{2} \mathrm{NRs}-2 \mathrm{H}$ are $2.41 \mathrm{eV}$, which are slightly lower than the $\mathrm{A}-\mathrm{SnO}_{2} \mathrm{NRs}$; this demonstrates that $\mathrm{Z}$ $\mathrm{SnO}_{2} \mathrm{NRs}-2 \mathrm{H}$ is more active than the other $\mathrm{SnO}_{2}$ nanoribbons.

Compared to the bare $\mathrm{SnO}_{2} \mathrm{NRs}$, the behavior of the $\mathrm{H}$ passivation nanoribbons changed significantly. The A$\mathrm{SnO}_{2} \mathrm{NRs}-\mathrm{OH}$ and $\mathrm{Z}-\mathrm{SnO}_{2} \mathrm{NRs}-2 \mathrm{H}$ remain semiconducting properties (the band gaps are $2.64 \mathrm{eV}$ and $2.41 \mathrm{eV}$, resp.), but the band gap of $\mathrm{A}-\mathrm{SnO}_{2} \mathrm{NRs}-\mathrm{OH}$ is obviously enhanced while the $\mathrm{Z}-\mathrm{SnO}_{2} \mathrm{NRs}-2 \mathrm{H}$ reduce. Similarly, we take the $\mathrm{A}_{8}$ $\mathrm{SnO}_{2} \mathrm{NR}-\mathrm{OH}$ (width $N=8$ ) as an example; the calculated band gap is $2.42 \mathrm{eV}$, slightly larger than $2.08 \mathrm{eV}$ of the bare armchair ribbon. For $\mathrm{Z}_{8}-\mathrm{SnO}_{2} \mathrm{NR}-2 \mathrm{H}$, the calculated band gap is $1.71 \mathrm{eV}$, obviously smaller than $2.19 \mathrm{eV}$ of the bare zigzag nanoribbon. The $\mathrm{A}_{8}-\mathrm{SnO}_{2} \mathrm{NR}-2 \mathrm{H}$ and $\mathrm{Z}_{8}-\mathrm{SnO}_{2} \mathrm{NR}-$ $\mathrm{OH}$ present the metallic property which supplied by the $2 \mathrm{p}$ state of edge $\mathrm{O}$ atoms and the $5 \mathrm{~s}$ state of the edge $\mathrm{Sn}$ atoms.

To further study the effect of external electronic field for $\mathrm{H}$ passivation $\mathrm{SnO}_{2} \mathrm{NRs}$, we calculate the evolutions of the band gap for $\mathrm{H}$ passivation with different external electric field in Figure 5. From Figure 5 we can find that because no pronounced differences are found when the field direction is reversed, owing to the symmetrical structure, $\mathrm{A}-\mathrm{SnO}_{2} \mathrm{NRs}-$ $\mathrm{OH}$ has a slower decreasing rate of the band gap with the increase of electric field and requires a larger critical electric field to close its band gap, which is similar to Kou et al. [22]. A vital reason is that the $\mathrm{A}-\mathrm{SnO}_{2} \mathrm{NRs}-\mathrm{OH}$ has larger band gaps than the bare ones and the unpaired electrons reduce when $\mathrm{H}$ atoms are introduced. For the $\mathrm{Z}-\mathrm{SnO}_{2} \mathrm{NRs}-2 \mathrm{H}$, the decreasing rate of the band gap is faster than $\mathrm{A}-\mathrm{SnO}_{2} \mathrm{NRs}-$ $\mathrm{OH}$ and it has a lower critical electric field of $0.13 \mathrm{eV}$ to close its band gap. This phenomenon well corresponds to the bare $\mathrm{SnO}_{2}$ nanoribbons. It illustrates that the $\mathrm{Z}-\mathrm{SnO}_{2} \mathrm{NRs}-2 \mathrm{H}$ are more sensitive to external electric field than $\mathrm{A}-\mathrm{SnO}_{2} \mathrm{NRs}-\mathrm{OH}$. There is special phenomenon that presents metallic property for $\mathrm{Z}-\mathrm{SnO}_{2} \mathrm{NRs}-\mathrm{OH}$ (the band gap is $0 \mathrm{eV}$ ) when it is without external electric field. Interestingly, it realizes a transformation from metal to semiconductor when the electric field reaches $0.07 \mathrm{eV} / \AA$. The band gap has the maximum value of $1.3 \mathrm{eV}$ when the external electric field increases to $0.15 \mathrm{eV} / \AA$ and subsequently the band gap decreases with the increase of the external electric field which is similar to Zheng et al. [41].

To reveal the underlying physical mechanism for the different $\mathrm{H}$ passivation models, band structure and the charge redistribution of the CBM and VBM are examined. Figures 6(a)-6(b) show band structure and the corresponding charge densities for $\mathrm{CBM}$ and $\mathrm{VBM}$ of $\mathrm{A}-\mathrm{SnO}_{2} \mathrm{NRs}-\mathrm{OH}$ at $0 \mathrm{v} / \mathrm{A}$ (a) and $0.15 \mathrm{v} / \AA \dot{A}$, respectively. From Figure 6(a), the charge distribution of the CBM almost concentrated at $\mathrm{O}$ atoms of 

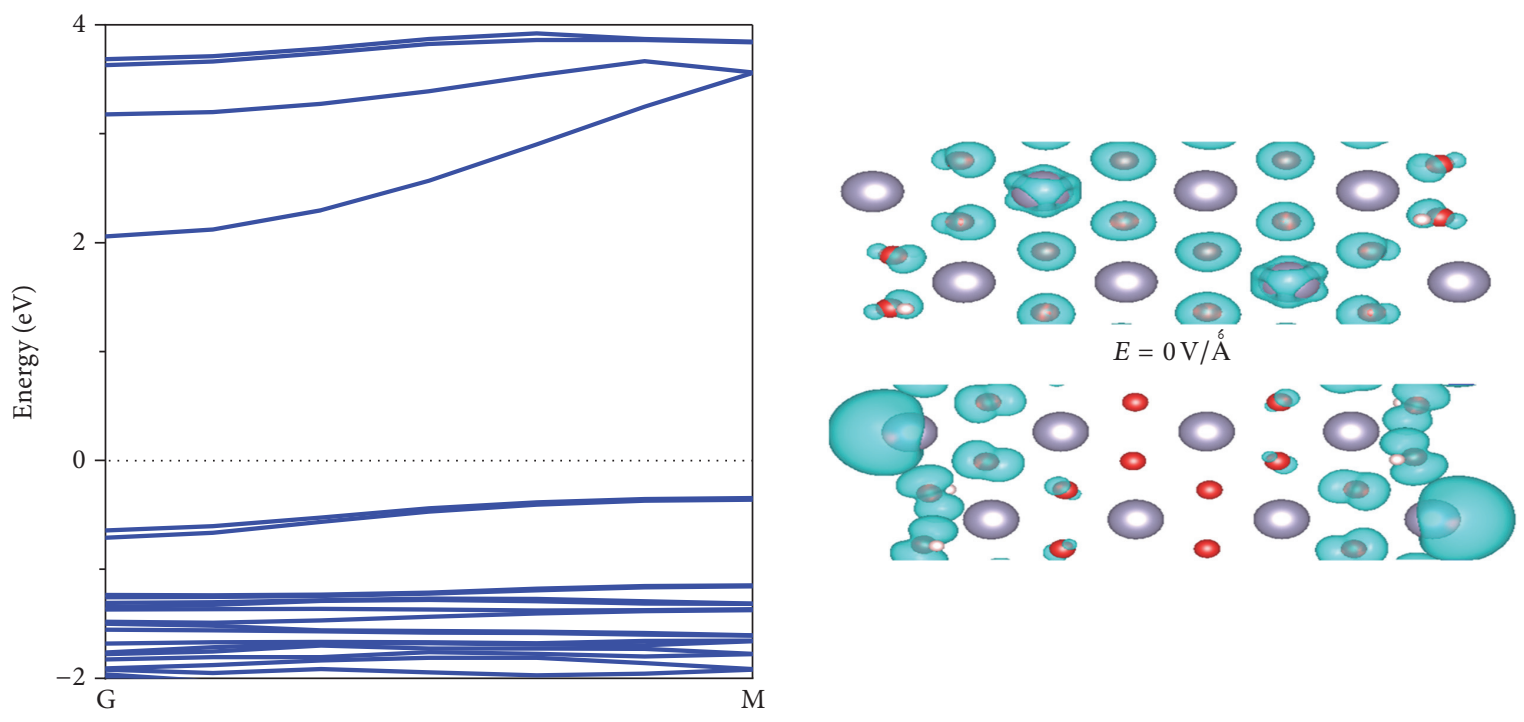

(a)
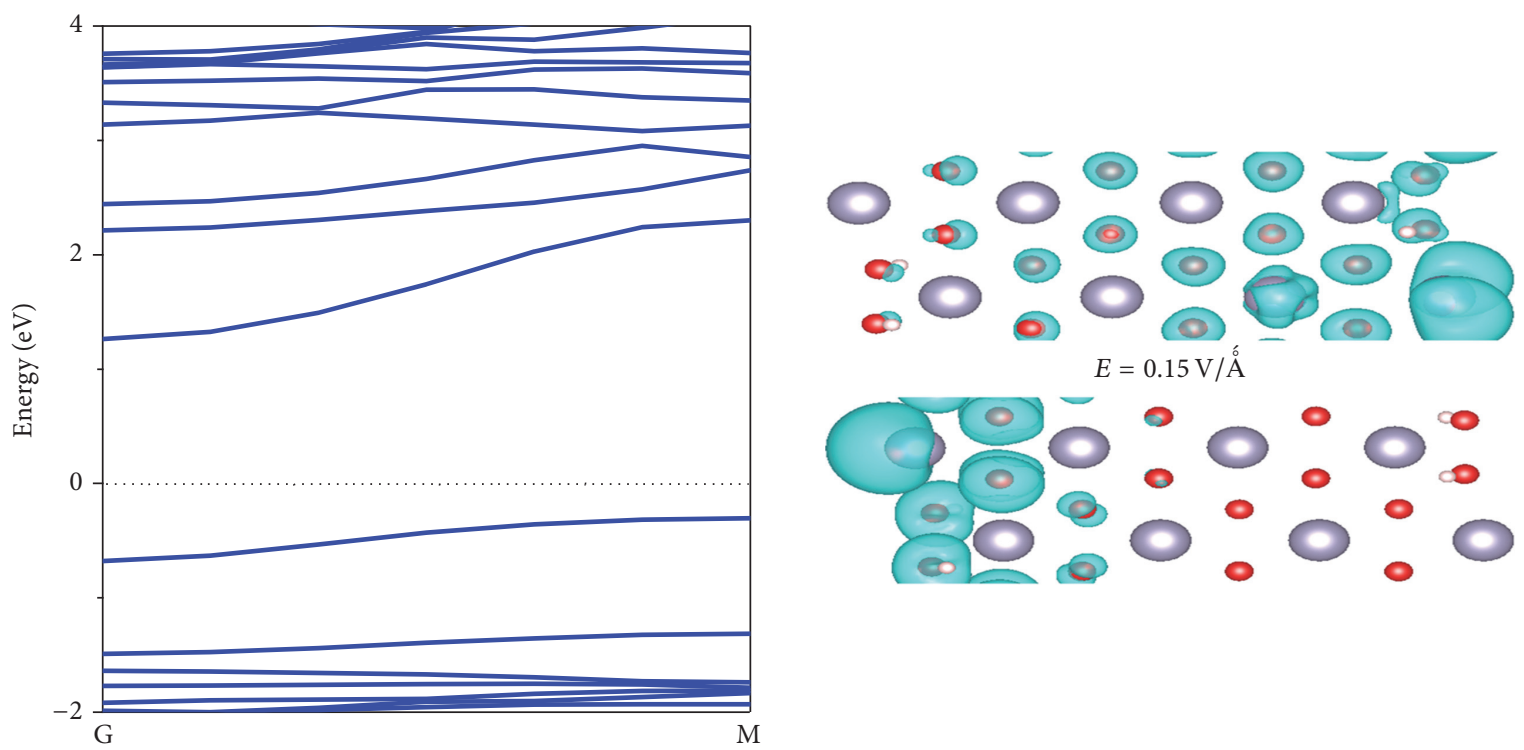

(b)

FIGURE 6: Band structure and the corresponding charge densities for CBM (right upper) and VBM (right lower) of $\mathrm{A}-\mathrm{SnO}{ }_{2} \mathrm{NRs}-\mathrm{OH}$ at $0 \mathrm{v} / \mathrm{A}$ (a) and $0.15 \mathrm{v} / \AA \AA^{\circ}$ (b). The isosurface is $5.0 \times 10^{-3} \mathrm{e} / \AA^{3}$. The Fermi level is shifted to zero.

the whole ribbon except for the ribbon edges, while the charge distribution of the VBM is totally concentrated at the $\mathrm{Sn}$ atoms and $\mathrm{O}$ atoms of the ribbon edges which is similar to the VBM of A-SnO ${ }_{2}$ NRs. Once an external electric field is applied, the charge distributions of the CBM and VBM are driven to localize at opposite edges owing to the different electrostatic potential, as analyzed above, as shown in Figure 6(b). This can shift down the CBM because the charge easily redistributes in external electric fields, while the VBM also obviously upshifts in energy band toward the Fermi level, thereby further narrowing the energy gap.

Band structure and the charge redistribution of $\mathrm{H}$ passivation $\mathrm{Z}-\mathrm{SnO}_{2} \mathrm{NRs}$ were presented in Figures 7 and 8 . From Figure 7, we can conclude that it is an indirect gap semiconductor regardless of whether or not the electric field is applied. The charges of CBM and VBM mainly concentrate at the $\mathrm{O}$ atoms and $\mathrm{Sn}$ atoms of the ribbon edges as shown in Figure 7(a). That is different from the bare $\mathrm{Z}-\mathrm{SnO}_{2} \mathrm{NRs}$ in which the charge mainly concentrates at the $\mathrm{O}$ atoms in whole nanoribbon. From Figure 7(b), under the electronic field of $0.2 \mathrm{v} / \mathrm{A}$, the charge distributions of the CBM and VBM are driven to localize at opposite edges; this situation is similar to the $\mathrm{A}-\mathrm{SnO}_{2} \mathrm{NRs}-\mathrm{OH}$. In Figure 8, the wave function of the CBM primarily localize at $\mathrm{O}$ atoms and $\mathrm{Sn}$ atoms of the nanoribbon center, whereas the wave function of VBM mainly concentrates at the $\mathrm{O}$ atoms of the whole nanoribbon and the $\mathrm{Sn}$ atoms of the right nanoribbon edge. The hydrogenation of $\mathrm{Z}-\mathrm{SnO}_{2} \mathrm{NRs}$ destructed the symmetry 

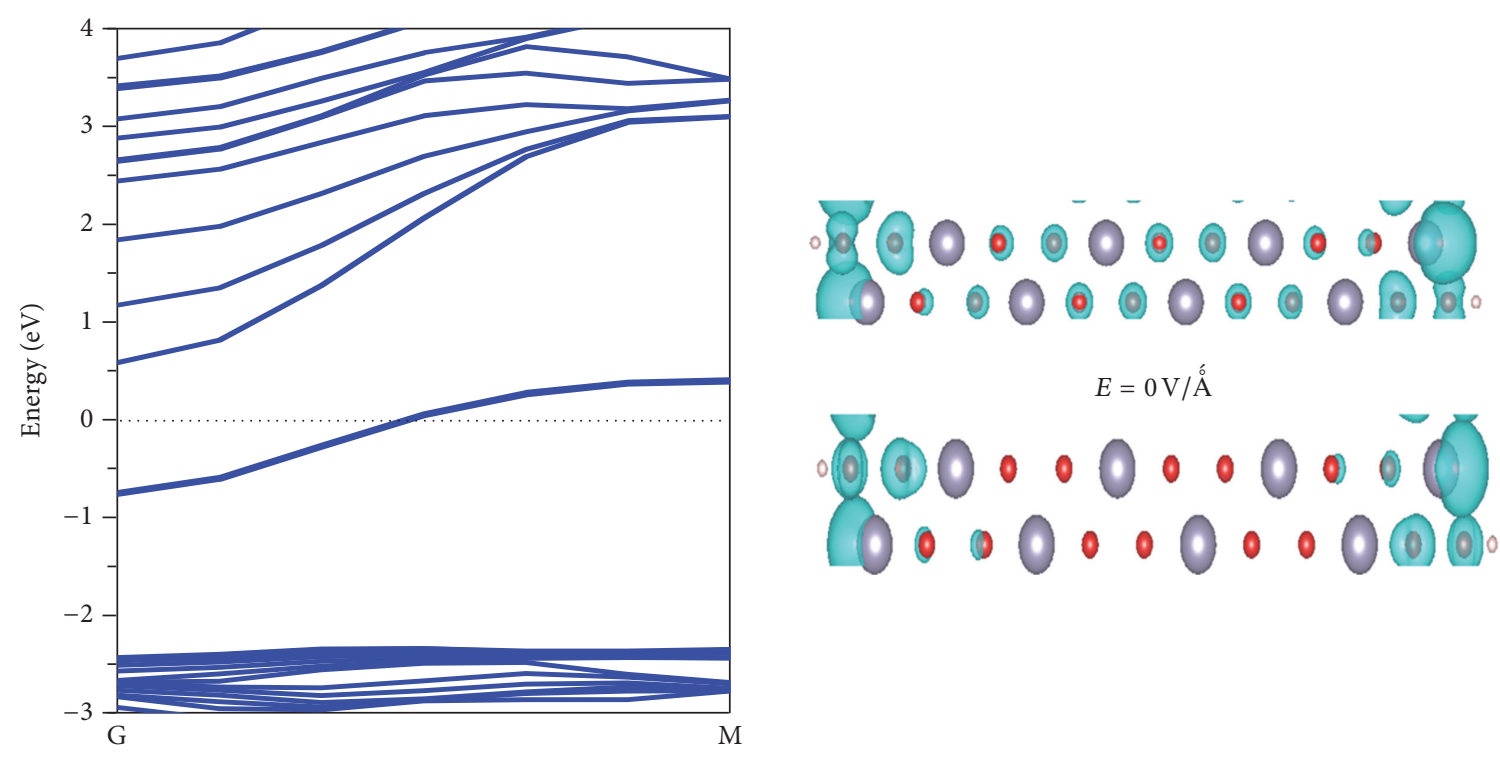

(a)
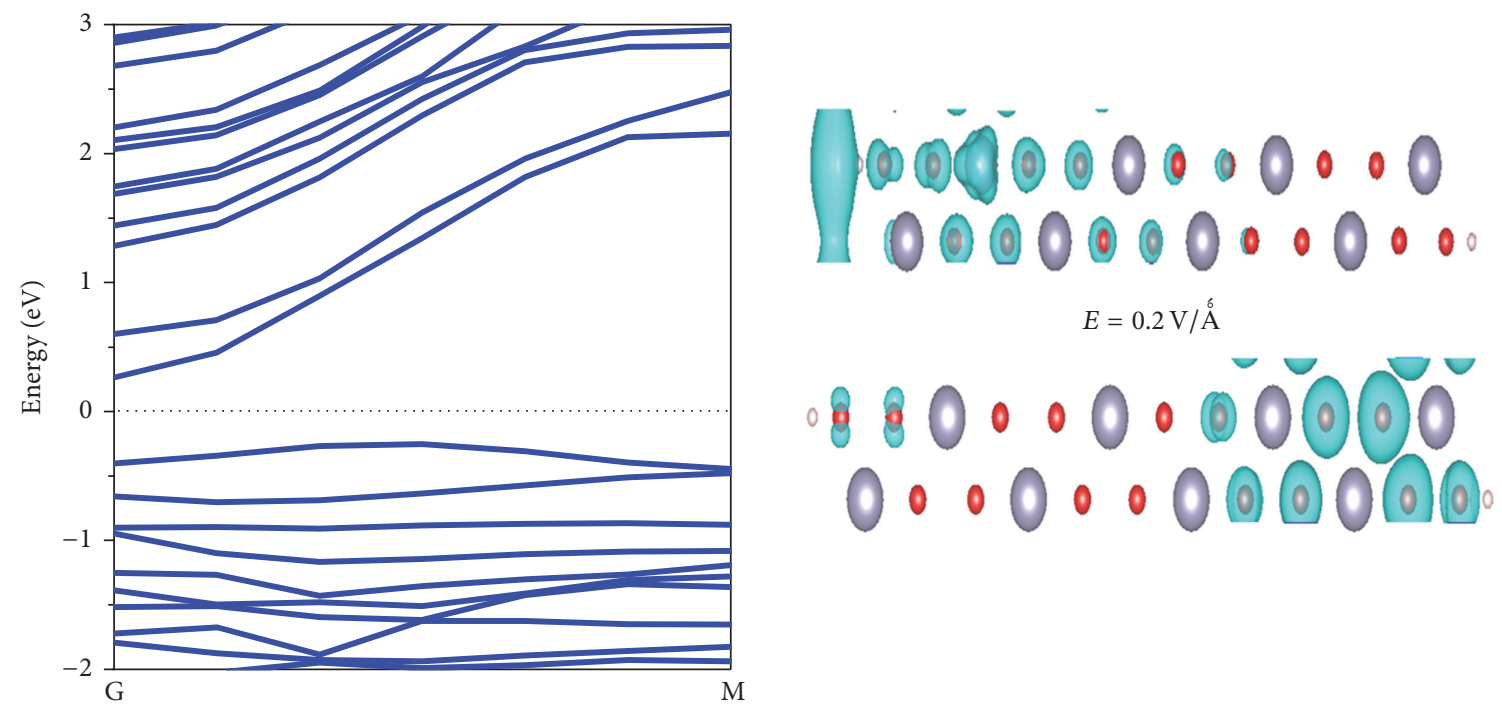

(b)

FIGURE 7: Band structure and the corresponding charge densities for CBM (right upper) and VBM (right lower) of Z-SnO $\mathrm{NRs}_{2} \mathrm{NH}$ at 0 v/Á (a) and $0.2 \mathrm{v} / \AA \hat{\mathrm{A}}$ (b). The isosurface is $5.0 \times 10^{-3} \mathrm{e} / \AA^{3}$. The Fermi level is shifted to zero.

of $\mathrm{Z}-\mathrm{SnO}_{2} \mathrm{NRs}-2 \mathrm{H}$, which made the charge densities for VBM of $\mathrm{Z}-\mathrm{SnO}_{2} \mathrm{NRs}-2 \mathrm{H}$ asymmetric, which we can see from Figure 8 . In addition, the charges are redistributed because the electrostatic potential symmetry is broken under an external electric field. The wave functions of the CBM and VBM states are localized at the opposite edge. This charge redistribution results in the transition of electrons between the valence and conduction band and splitting of the subband levels. Subsequently, this makes the decreasing of the band gaps and enhances the conductivity of the $\mathrm{SnO}_{2} \mathrm{NRs}$ materials.

3.3. Electronic Transport. The lower dimension semiconductors are usually used to fabricate electronic transport devices, such as graphene and silicone nanoribbon [42, 43]. The electronic transmission of $\mathrm{SnO}_{2}$ nanoribbon can be explored in terms of transport property. The transmission of $\mathrm{SnO}_{2}$ nanoribbon is determined with two probe methods. The two ends of $\mathrm{SnO}_{2}$ nanoribbon are held within the electrodes. The width of left electrode and right electrode is $3.15 \AA$, respectively, as shown in Figure 1(h). The electrons near the Fermi level contribute to electronic transport property in $\mathrm{SnO}_{2}$ nanoribbon. The orbital delocalization near the Fermi level results in high mobility of electrons which corresponds to certain peak amplitudes in the transmission spectrum $[44,45]$. The current through the system is calculated using the Landauer-Büttiker formula: $I=(2 e / h) \int T(E, V)\left[f_{L}(E-\right.$ $\left.\left.\mu_{L}\right)-f_{R}\left(E-\mu_{R}\right)\right] d E[46,47]$, where $e$ is the electron charge, $h$ is Planck's constant, $T(E, V)$ is the transmission 


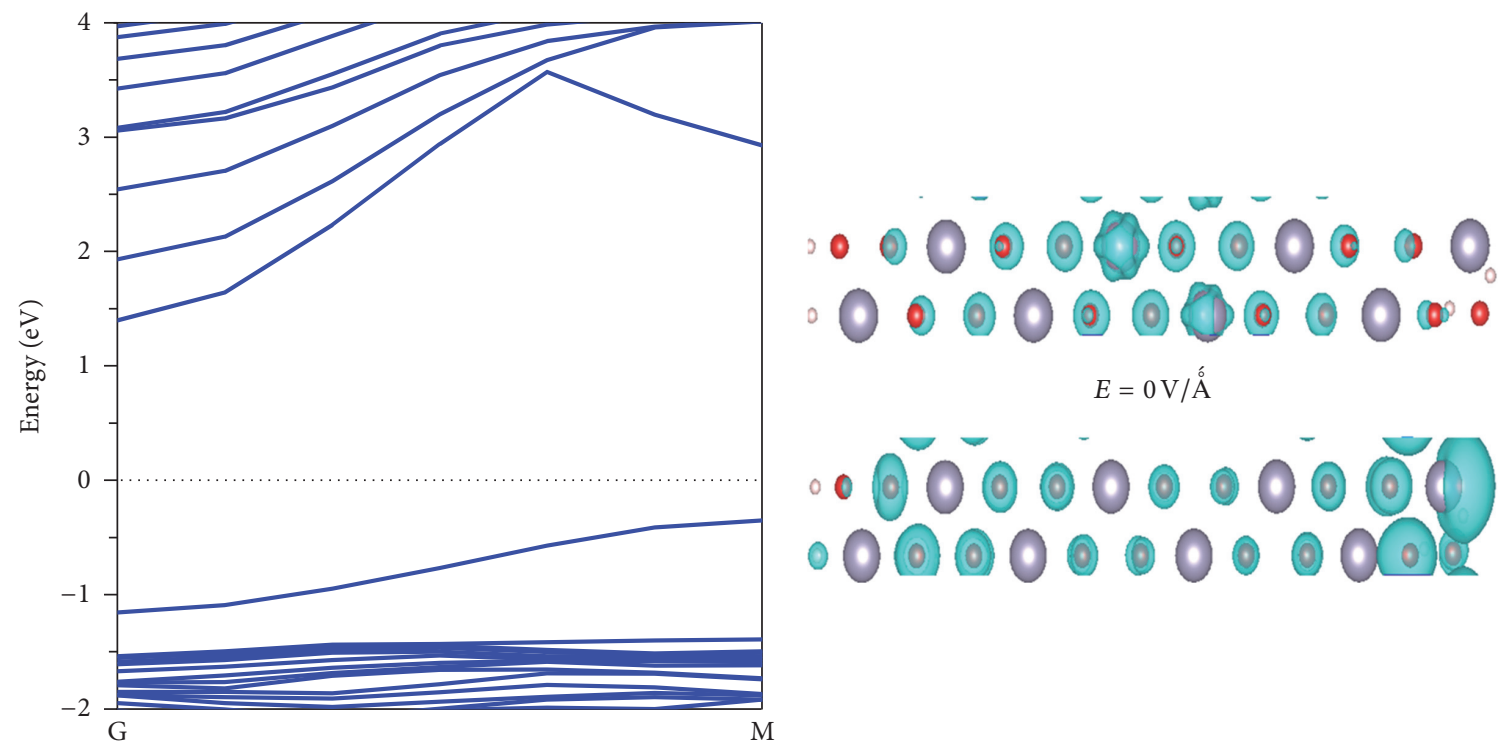

(a)
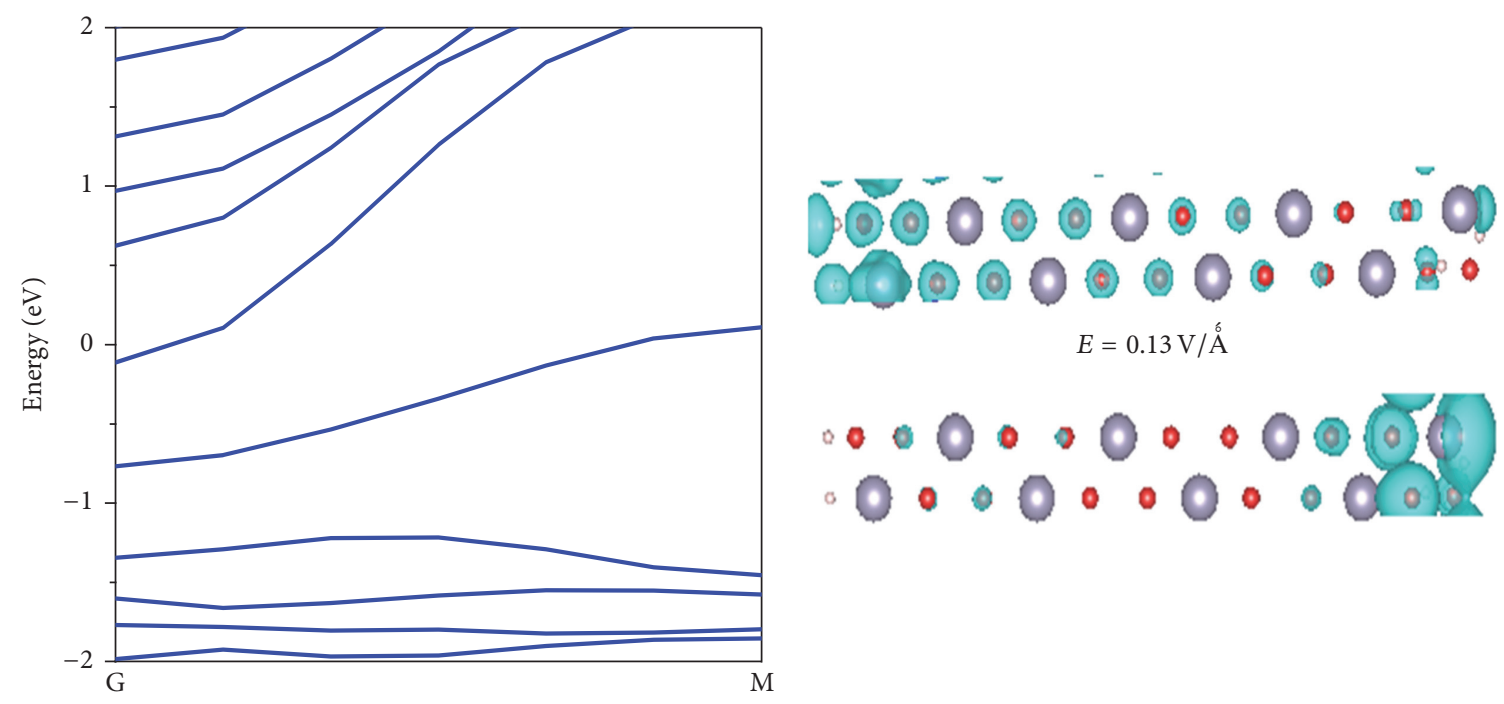

(b)

FIGURE 8: Band structure and the corresponding charge densities for CBM (right upper) and VBM (right lower) of Z-SnO 2 NRs-2H at $0 \mathrm{v} / \mathrm{A}$ (a) and $0.13 \mathrm{v} / \AA \AA^{\circ}$ (b). The isosurface is $5.0 \times 10^{-3} \mathrm{e} / \AA^{3}$. The Fermi level is shifted to zero.

probability through the junction for an electron at energy $E$ and an applied bias voltage $V, f_{L / R}\left(E-\mu_{L / R}\right)$ is the FermiDirac distribution function, and $\mu_{L}, \mu_{R}$ is the electrochemical potential of the left and right electrode, respectively.

The electronic transmission is invoked with magnitude of transmission in a particular energy interval. Figure 9 represents the transmission spectrum of $\mathrm{A}-\mathrm{SnO}_{2} \mathrm{NRs}$ and $\mathrm{Z}$ $\mathrm{SnO}_{2} \mathrm{NRs}$. The width of the center scattering region is $0.02 \mathrm{eV}$ and $0.05 \mathrm{eV}$ for $\mathrm{A}-\mathrm{SnO}_{2} \mathrm{NRs}$ and $\mathrm{Z}-\mathrm{SnO}_{2} \mathrm{NRs}$, respectively. For $\mathrm{A}-\mathrm{SnO}_{2} \mathrm{NRs}$, the transmission peaks are observed for $-2.8 \mathrm{~V},-2.4 \mathrm{~V}$, and $-1.7 \mathrm{~V}$ in the valence band and $1.5 \mathrm{~V}$ and $2.8 \mathrm{~V}$ in the conduction band. Compared with $\mathrm{A}-\mathrm{SnO}_{2} \mathrm{NRs}$, more peaks of $\mathrm{Z}-\mathrm{SnO}_{2} \mathrm{NRs}$ are observed in the valence band. The peaks locate at $-2.8 \mathrm{~V},-2.5 \mathrm{~V},-1.7 \mathrm{~V}$, and $-1.1 \mathrm{~V}$ in valence band; the location of peaks is similar to $\mathrm{A}-\mathrm{SnO}_{2} \mathrm{NRs}$ in conduction band. This is also in agreement with the electron density of $\mathrm{Z}-\mathrm{SnO}_{2} \mathrm{NRs}$, where the electron density is more intense than $\mathrm{A}-\mathrm{SnO}_{2} \mathrm{NRs}$. In addition, compared to $\mathrm{Z}-\mathrm{SnO}_{2} \mathrm{NRs}, \mathrm{A}-\mathrm{SnO}_{2} \mathrm{NRs}$ has a larger cutting area near the Fermi surface, which is closely related to a larger band gap for $\mathrm{A}-\mathrm{SnO}_{2} \mathrm{NRs}$, which also shows that the transmission spectrum of materials has close correlation for electronic density of states.

The calculated $I-V$ characteristics of $\mathrm{SnO}_{2} \mathrm{NRs}$ are illuminated in Figure 10. From Figure 10 we can find that the $\mathrm{A}-\mathrm{SnO}_{2} \mathrm{NR}$ and $\mathrm{Z}-\mathrm{SnO}_{2} \mathrm{NR}$ are in off state when the bias voltage is between $-0.3 \mathrm{~V}$ and $0.3 \mathrm{~V}$. When the bias voltage exceeds $0.3 \mathrm{~V}$, the current presents a nonlinear increase and 


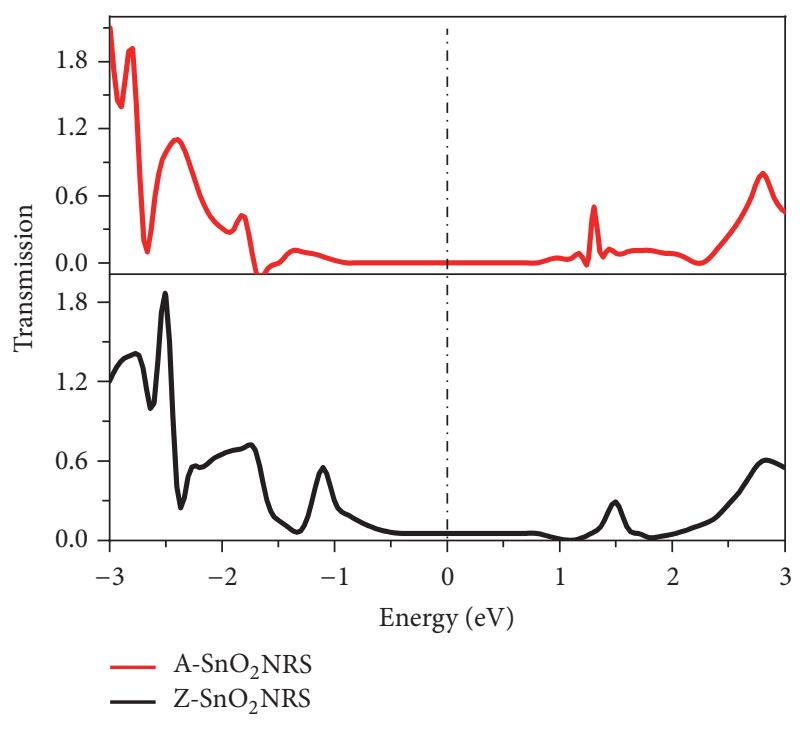

FIgURE 9: Transmission spectrums of $\mathrm{SnO}_{2}$ nanoribbons.

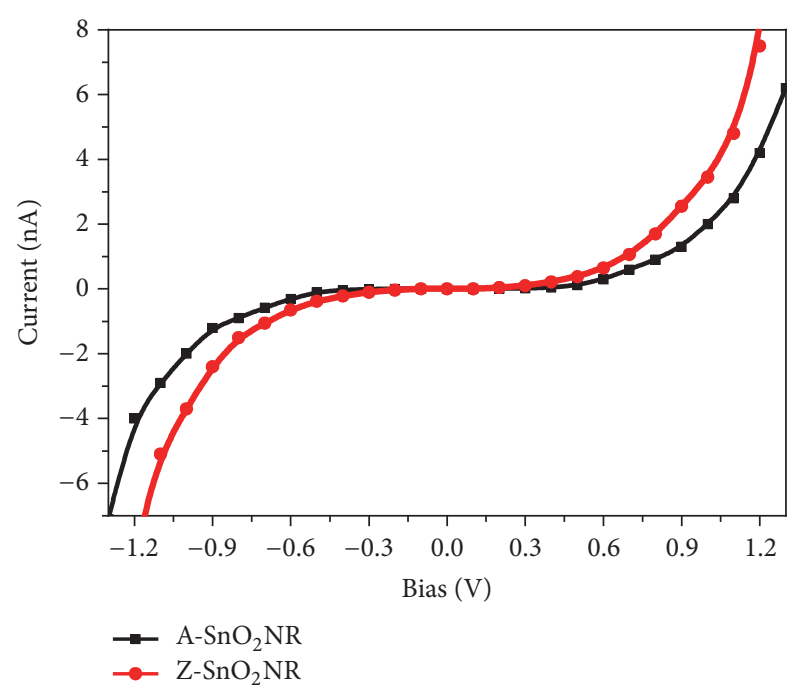

FIgURE 10: The calculated $I-V$ characteristics of $\mathrm{SnO}_{2}$ nanoribbons.

same change trend for $\mathrm{A}-\mathrm{SnO}_{2} \mathrm{NR}$ and $\mathrm{Z}-\mathrm{SnO}_{2} \mathrm{NR}$, similar to the electrons conduction of the other semiconductors, such as $\mathrm{ZnO}$ and $\mathrm{TiO}_{2}$. Since $0.8 \mathrm{~V}$, the change of the bias voltage not only produces the conduction current, which also makes the current have a nonlinear growth; this phase of the $V$ - $I$ characteristic curve is similar to general electronic conduction semiconductor devices. The difference of the $I-V$ curve can be explained by the fact that the $\mathrm{A}-\mathrm{SnO}_{2} \mathrm{NR}$ and $\mathrm{Z}-\mathrm{SnO}_{2} \mathrm{NR}$ possess the different band gap and voltage sensitivity. The thickness of $\mathrm{SnO}_{2} \mathrm{NR}$ is similar to the thickness of three atoms and two-dimensional electron gas can be formed; in addition, similar to the graphene, $\mathrm{SnO}_{2}$ can be self-assembled on the experimental generation. Based on these special electronic transport properties, the $\mathrm{SnO}_{2}$ nanoribbons have enormous potential application in the switching, rectifying devices and the whole semiconductor industry.

\section{Conclusions}

In summary, the electronic structures and band gap modulations of the $\mathrm{Z}-\mathrm{SnO}_{2} \mathrm{NRs}$ and $\mathrm{A}-\mathrm{SnO}_{2} \mathrm{NRs}$ influenced by an external transverse electronic field and hydrogen passivation have been investigated by using the first-principle PAW potential within the DFT framework under GGA. As affected by a transverse electric field, the band gaps of bare $\mathrm{Z}-\mathrm{SnO}_{2} \mathrm{NRs}$ and $\mathrm{A}-\mathrm{SnO}_{2} \mathrm{NRs}$ demonstrate a remarkable reduction and the semiconductor-metal transition would appear at a lower value of critical electric field. The charge density near the Fermi can be redistributed. For the $\mathrm{SnO}_{2} \mathrm{NRs}$ with edge hydrogen termination through different way, the Z$\mathrm{SnO}_{2} \mathrm{NRs}-2 \mathrm{H}$ and $\mathrm{A}-\mathrm{SnO}_{2} \mathrm{NRs}-\mathrm{OH}$ remain semiconducting properties, but the change of the band gap for the A$\mathrm{SnO}_{2} \mathrm{NRs}-\mathrm{OH}$ and $\mathrm{Z}-\mathrm{SnO}_{2} \mathrm{NRs}-2 \mathrm{H}$ is obviously different. The $\mathrm{Z}-\mathrm{SnO}_{2} \mathrm{NRs}-2 \mathrm{H}$ are more sensitive to external electric field than $\mathrm{A}-\mathrm{SnO}_{2} \mathrm{NRs}-\mathrm{OH}$. For the $\mathrm{Z}-\mathrm{SnO}_{2} \mathrm{NRs}-\mathrm{OH}$, it can realize transformation from metal to semiconductor when the electric field reaches $0.07 \mathrm{eV} / \AA$. Additionally, it indicates that more peaks of $\mathrm{Z}-\mathrm{SnO}_{2} \mathrm{NRs}$ are observed in the valence band compared with $\mathrm{A}-\mathrm{SnO}_{2} \mathrm{NRs}$ by electronic transport properties. There is similar variation tendency of the $I$ $V$ characteristics of both $\mathrm{A}-\mathrm{SnO}_{2} \mathrm{NR}$ and $\mathrm{Z}-\mathrm{SnO}_{2} \mathrm{NR}$. Our results may be very useful theoretical reference to design nanoelectronic and spintronic devices.

\section{Conflicts of Interest}

The authors declare no competing financial interest.

\section{Acknowledgments}

This work was supported by the National Natural Science Foundation of China (Grants nos. 61571210, 61172028, 11274143, and 11304121), the Natural Science Foundation of Shandong Province (Grant no. ZR2010EL017), and Research Fund for the Doctoral of University of Jinan (Grant no. XBS1452).

\section{References}

[1] K. S. Novoselov, A. K. Geim, S. V. Morozov et al., "Electric field in atomically thin carbon films," Science, vol. 306, no. 5696, pp. 666-669, 2004.

[2] Y.-W. Son, M. L. Cohen, and S. G. Louie, "Half-metallic graphene nanoribbons," Nature, vol. 444, no. 7117, pp. 347-349, 2006.

[3] X. Li, X. Wang, L. Zhang, S. Lee, and H. Dai, "Chemically derived, ultrasmooth graphene nanoribbon semiconductors," Science, vol. 319, no. 5867, pp. 1229-1232, 2008.

[4] E.-J. Kan, H. J. Xiang, J. Yang, and J. G. Hou, "Electronic structure of atomic $\mathrm{Ti}$ chains on semiconducting graphene nanoribbons: a first-principles Study," Journal of Chemical Physics, vol. 127, no. 16, Article ID 164706, 2007.

[5] Q. Yan, B. Huang, J. Yu et al., "Intrinsic current-voltage characteristics of graphene nanoribbon transistors and effect of edge doping," Nano Letters, vol. 7, no. 6, pp. 1469-1473, 2007. 
[6] P. Koskinen, S. Malola, and H. Häkkinen, "Self-passivating edge reconstructions of graphene," Physical Review Letters, vol. 101, no. 11, Article ID 115502, 2008.

[7] D. L. Miller, K. D. Kubista, G. M. Rutter et al., "Structural analysis of multilayer graphene via atomic moiré interferometry," Physical Review B, vol. 81, no. 12, Article ID 125427, 2010.

[8] K. S. Novoselov, D. Jiang, F. Schedin et al., "Two-dimensional atomic crystals," Proceedings of the National Academy of Sciences of the United States of America, vol. 102, no. 30, pp. 10451-10453, 2005.

[9] S. Z. Butler, S. M. Hollen, L. Cao et al., "Progress, challenges, and opportunities in two-dimensional materials beyond graphene," ACS Nano, vol. 7, no. 4, pp. 2898-2926, 2013.

[10] F.-F. Zhu, W.-J. Chen, Y. Xu et al., "Epitaxial growth of twodimensional stanene," Nature Materials, vol. 14, no. 10, pp.10201025, 2015.

[11] B. Peng, H. Zhang, H. Shao, Y. Xu, X. Zhang, and H. Zhu, "Low lattice thermal conductivity of stanene," Scientific Reports, vol. 6, Article ID 20225, 2016.

[12] W. Xiong, C. Xia, T. X. Wang, Y. Peng, and Y. Jia, "Strain and spin-orbital coupling effects on electronic structures and magnetism of semi-hydrogenated stanene," The Journal of Physical Chemistry C, vol. 120, no. 19, pp. 10622-10628, 2016.

[13] T. Osaka, H. Omi, K. Yamamoto, and A. Ohtake, "Surface phase transition and interface interaction in the -Sn/InSbl11 system," Physical Review B, vol. 50, no. 11, pp. 7567-7572, 1994.

[14] M. Modarresi, A. Kakoee, Y. Mogulkoc, and M. R. Roknabadi, "Effect of external strain on electronic structure of stanene," Computational Materials Science, vol. 101, pp. 164-167, 2015.

[15] C.-C. Ren, W.-X. Ji, C.-W. Zhang, P. Li, and P.-J. Wang, "The effects of biaxial strain and electric field on the electronic properties in stanene," Materials Research Express, vol. 3, no. 10, Article ID 105008, 2016.

[16] S. S. Li and C. W. Zhang, "Tunable electronic structures and magnetic properties in two-dimensional stanene with hydrogenation," Materials Chemistry and Physics, vol. 173, pp. 246254, 2016.

[17] D. Prezzi, D. Varsano, A. Ruili, A. Marini, and E. Molinari, "Optical properties of graphene nanoribbons: the role of manybody effects," Physical Review B: Condensed Matter and Materials Physics, vol. 77, Article ID 041404, 2008.

[18] W. Chen, Y. Li, G. Yu et al., "Hydrogenation: a simple approach to realize semiconductor-half-metal-metal transition in boron nitride nanoribbons," Journal of the American Chemical Society, vol. 132, no. 5, pp. 1699-1705, 2010.

[19] Y. Li, Z. Zhou, S. Zhang, and Z. Chen, "MoS2 nanoribbons: high stability and unusual electronic and magnetic properties," Journal of the American Chemical Society, vol. 130, no. 49, pp. 16739-16744, 2008.

[20] H. Pan and Y.-W. Zhang, "Edge-dependent structural, electronic and magnetic properties of MoS2 nanoribbons," Journal of Materials Chemistry, vol. 22, no. 15, pp. 7280-7290, 2012.

[21] A. R. Botello-Méndez, F. López-Urías, M. Terrones, and H. Terrones, "Magnetic behavior in zinc oxide zigzag nanoribbons," Nano Letters, vol. 8, no. 6, pp. 1562-1565, 2008.

[22] L. Kou, C. Li, Z. Zhang, and W. Guo, "Electric-field- and hydrogen-passivation-induced band modulations in armchair ZnO nanoribbons," Journal of Physical Chemistry C, vol. 114, no. 2, pp. 1326-1330, 2010.

[23] T. He, F. Pan, Z. Xi et al., "First-principles study of titania nanoribbons: formation, energetics, and electronic properties,"
Journal of Physical Chemistry C, vol. 114, no. 20, pp. 9234-9238, 2010.

[24] S. Ferrere, A. Zaban, and B. A. Gregg, "Dye sensitization of nanocrystalline tin oxide by perylene derivatives," Journal of Physical Chemistry B, vol. 101, no. 23, pp. 4490-4493, 1997.

[25] M. Khan, J. Xu, N. Chen, and W. Cao, "First principle calculations of the electronic and optical properties of pure and (Mo, $\mathrm{N})$ co-doped anatase TiO2," Journal of Alloys and Compounds, vol. 513, pp. 539-545, 2012.

[26] H. Takakura, M.-S. Choe, and Y. Hamakawa, "Paint-ondiffusant $\mathrm{SnO}_{2} / \mathrm{n}^{+}$-p Si heteroface solar cell," Japanese Journal of Applied Physics, vol. 19, no. 19, pp. 61-65, 1980.

[27] Z. Zhang, C. Shao, X. Li et al., "Electrospun nanofibers of ZnO$\mathrm{SnO} 2$ heterojunction with high photocatalytic activity," Journal of Physical Chemistry C, vol. 114, no. 17, pp. 7920-7925, 2010.

[28] S. Tamura, T. Ishida, H. Magara, T. Mihara, O. Tabata, and T. Tatsuta, "Transparent conductive tin oxide films by photochemical vapour deposition," Thin Solid Films, vol. 343-344, no. 1-2, pp. 142-144, 1999.

[29] H. J. Snaith and C. Ducati, "SnO2-Based dye-sensitized hybrid solar cells exhibiting near unity absorbed photon-to-electron conversion efficiency," Nano Letters, vol.10, no. 4, pp. 1259-1265, 2010.

[30] R.-S. Zhang, Y. Liu, Q. Gao et al., "First-principles study on the electronic and optical properties of $\mathrm{F}$ - and $\mathrm{Nb}$-doped anatase TiO2," Journal of Alloys and Compounds, vol. 509, no. 37, pp. 9178-9182, 2011.

[31] D. O. Scanlon and G. W. Watson, "On the possibility of p-type $\mathrm{SnO}_{2}$," Journal of Materials Chemistry, vol. 22, no. 48, pp. 2523625245, 2012.

[32] A. Schleife, J. B. Varley, F. Fuchs et al., "Tin dioxide from first principles: quasiparticle electronic states and optical properties," Physical Review B: Condensed Matter and Materials Physics, vol. 87, Article ID 239901, 2013.

[33] G. Rahman, V. M. García-Suárez, and J. M. Morbec, "Intrinsic magnetism in nanosheets of $\mathrm{SnO} 2$ : a first-principles study," Journal of Magnetism and Magnetic Materials, vol. 328, pp. 104108, 2013.

[34] B.-J. Huang, F. Li, C.-W. Zhang, P. Li, and P.-J. Wang, "Electronic structure and optical properties of Ag-doped $\mathrm{SnO}_{2}$ nanoribbons," RSC Advances, vol. 4, no. 79, pp. 41819-41824, 2014.

[35] G. Kresse and D. Joubert, "From ultrasoft pseudopotentials to the projector augmented-wave method," Physical Review B, vol. 59, no. 3, pp. 1758-1775, 1999.

[36] J. P. Perdew, K. Burke, and M. Ernzerhof, "Generalized gradient approximation made simple," Physical Review Letters, vol. 77, no. 18, pp. 3865-3868, 1996.

[37] H. J. Monkhorst and J. D. Pack, "Special points for Brillouinzone integrations," Physical Review. B. Solid State, vol. 13, no. 12, pp. 5188-5192, 1976.

[38] Z. Zhang and W. Guo, "Energy-gap modulation of BN ribbons by transverse electric fields: first-principles calculations," Physical Review B-Condensed Matter and Materials Physics, vol. 77, no. 7, Article ID 075403, 2008.

[39] C.-W. Chen, M.-H. Lee, and S. J. Clark, “Band gap modification of single-walled carbon nanotube and boron nitride nanotube under a transverse electric field," Nanotechnology, vol. 15, no. 12, pp. 1837-1843, 2004.

[40] K. H. Khoo, M. S. C. Mazzoni, and S. G. Louie, "Tuning the electronic properties of boron nitride nanotubes with transverse electric fields: a giant dc Stark effect," Physical Review B, vol. 69, no. 20, Article ID 201401, 2004. 
[41] F. Zheng, Z. Liu, J. Wu, W. Duan, and B.-L. Gu, "Scaling law of the giant Stark effect in boron nitride nanoribbons and nanotubes," Physical Review B-Condensed Matter and Materials Physics, vol. 78, no. 8, Article ID 085423, 2008.

[42] H. Goto, E. Uesugi, R. Eguchi, A. Fujiwara, and Y. Kubozono, "Edge-dependent transport properties in graphene," Nano Letters, vol. 13, no. 3, pp. 1126-1130, 2013.

[43] R. Quhe, R. Fei, Q. Liu et al., "Tunable and sizable band gap in silicene by surface adsorption," Scientific Reports, vol. 2, article 853, 2012.

[44] S. Yamacli, "Comparison of the electronic transport properties of metallic graphene and silicene nanoribbons," Journal of Nanoparticle Research, vol. 16, no. 8, article 2576, 2014.

[45] H. Fueno, Y. Kobayashi, and K. Tanaka, "Theoretical study of current-voltage characteristics of carbon nanotube wire functionalized with hydrogen atoms," Science China Chemistry, vol. 55, no. 5, pp. 796-801, 2012.

[46] M. Büttiker, Y. Imry, R. Landauer, and S. Pinhas, "Generalized many-channel conductance formula with application to small rings," Physical Review B, vol. 31, no. 10, pp. 6207-6215, 1985.

[47] D. Zha, C. Chen, and J. Wu, "Electronic transport through a silicene-based zigzag and armchair junction," Solid State Communications, vol. 219, pp. 21-24, 2015. 

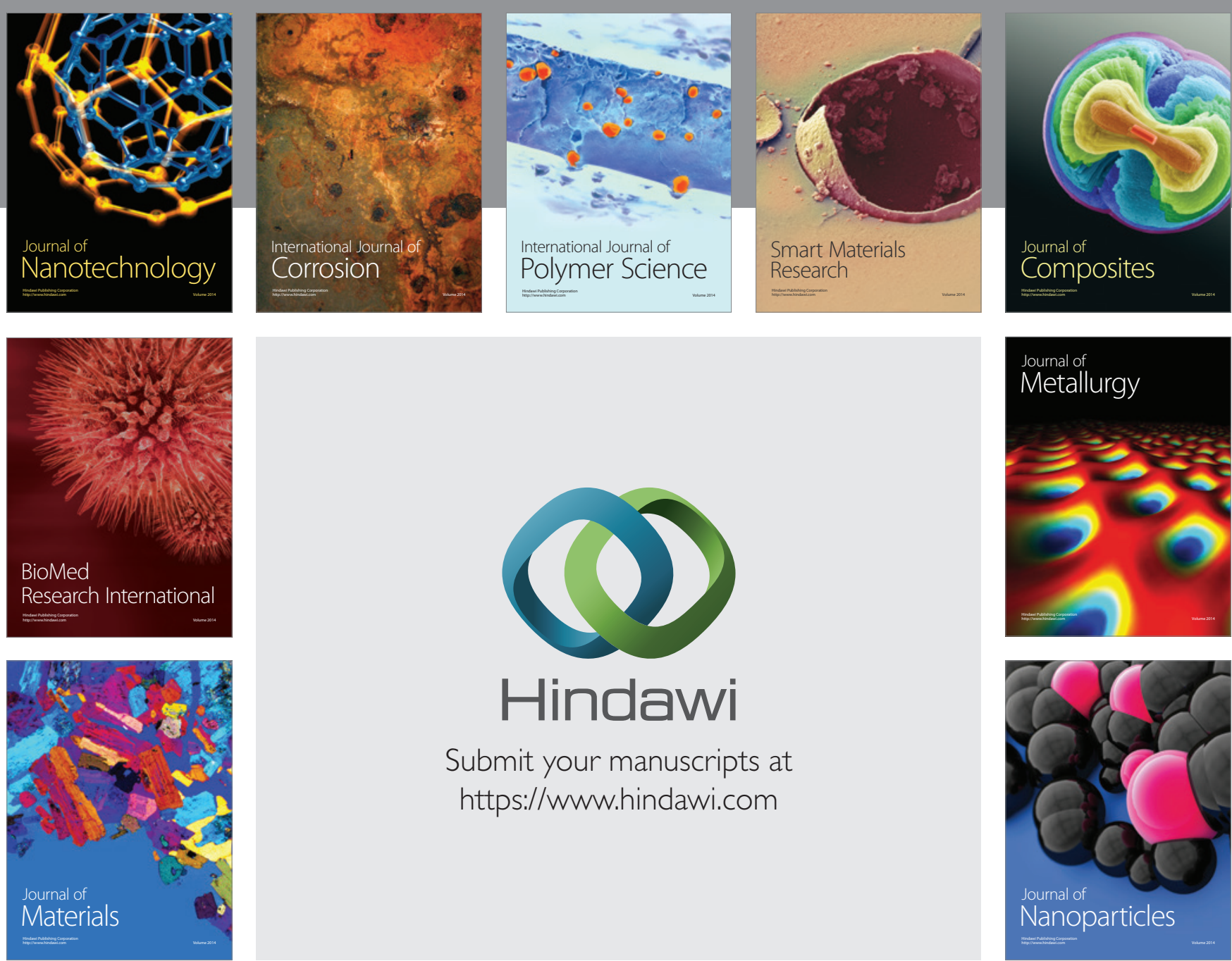

\section{Hindawi}

Submit your manuscripts at

https://www.hindawi.com

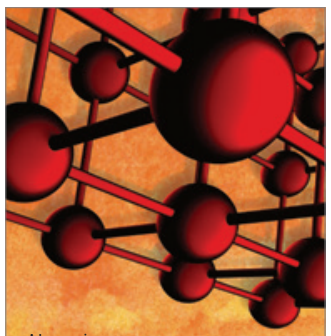

Materials Science and Engineering
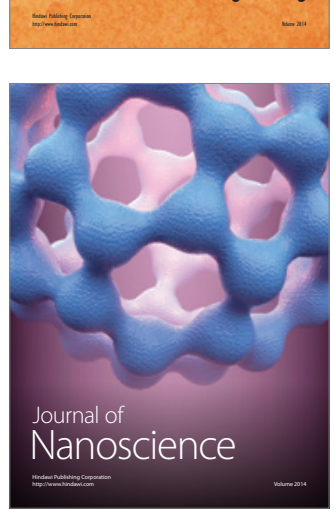
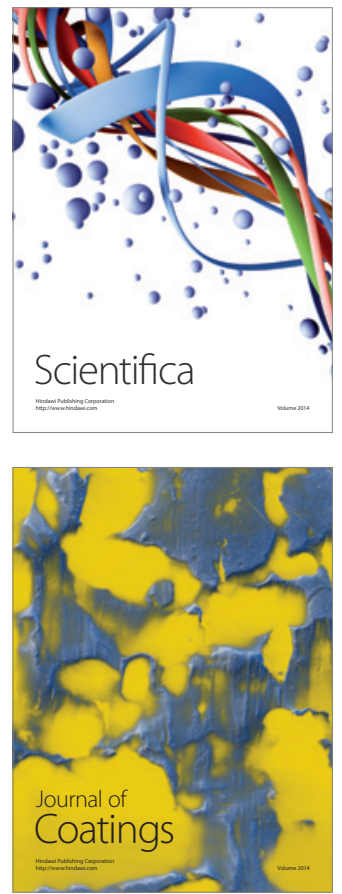
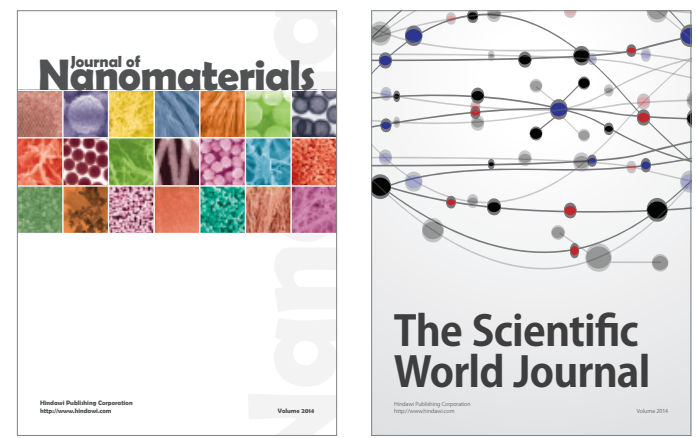

The Scientific World Journal
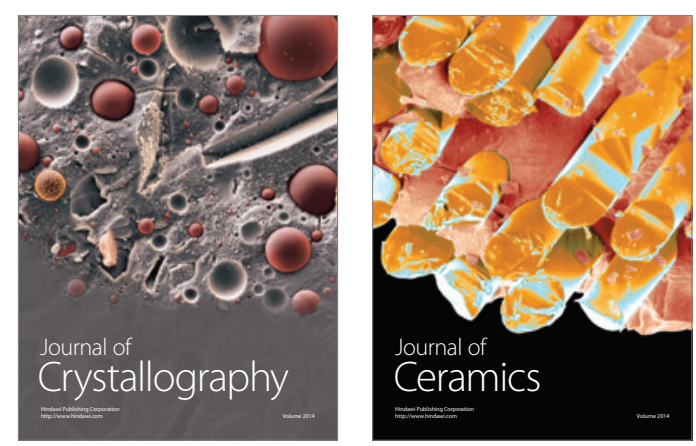
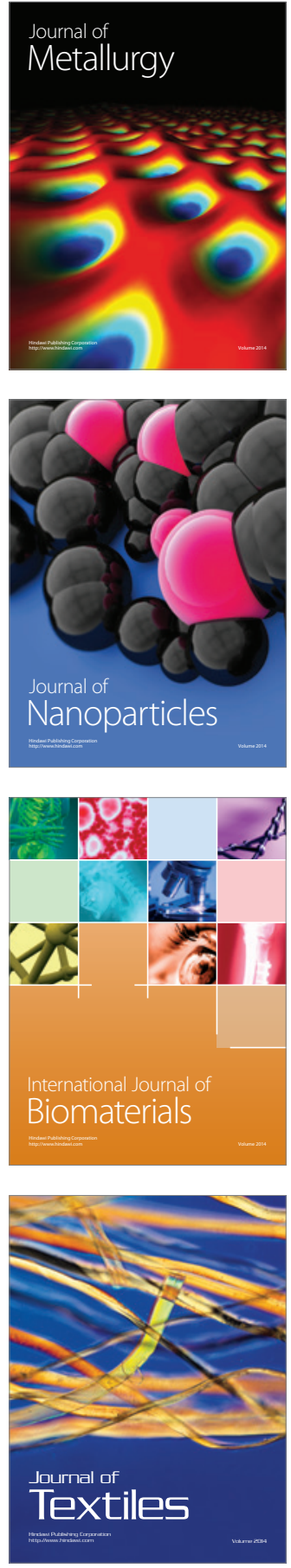